\title{
Cyclic-GMP Enhances Light-Induced Excitation and Induces Membrane Currents in Drosophila Retinal Photoreceptors
}

\author{
Juan Bacigalupo,' Diana M. Bautista, ${ }^{2}$ Deidre L. Brink, ${ }^{2}$ Jane F. Hetzer, ${ }^{2}$ and Peter M. O'Day ${ }^{2}$ \\ 'Universidad de Chile, Facultad de Ciencias, Departmento de Biologia, Casilla 653, Santiago, Chile and ${ }^{2}$ Institute of \\ Neuroscience, University of Oregon, Eugene, Oregon 97403-1254
}

\begin{abstract}
Phototransduction in the Drosophila retina appears to require the phosphoinositide signaling cascade following receptor/G-protein activation. Subsequent opening of membrane cationic channels causes excitation. The biochemical events underlying channel opening and regulation of sensitivity remain largely unknown. Evidence is mounting that phototransduction in Drosophila and other invertebrate species may additionally involve the second messenger, cyclic-GMP (cGMP). We report that exogenous cGMP influenced Drosophila retinal phototransduction in two ways. In whole cell tight-seal voltage-clamp experiments, membrane permeant cGMP analog, 8-bromo-cyclic-GMP (8Br-cGMP), induced membrane currents and dramatically enhanced light-induced currents. The currents induced by 8-Br-cGMP possessed reversal potentials similar to those induced by light. The magnitudes of cGMP-induced currents exhibited marked dependence on intensity of background illumination. Potential direct or modulatory roles of cGMP in Drosophila phototransduction are discussed.
\end{abstract}

[Key words: cyclic-GMP, phototransduction, invertebrate, electrophysiology, phosphoinositide, Drosophila, retina]

In the Drosophila retina, intracellular phosphoinositide (PI) chemistry is at the heart of visual transduction (reviews: Ranganathan et al., 1991b; Hardie and Minke, 1993). The light receptor molecule (rhodopsin), through G-protein mediation (Lee et al., 1990, 1994; Dolph et al., 1993), activates phospholipase C. Resulting PI-hydrolysis (Devary et al., 1987; Selinger and Minke, 1988) leads to elevation of intracellular $\left[\mathrm{Ca}^{2+}\right]$ (Ranganathan et al., 1994; Peretz et al., 1994). The link between PIhydrolysis and membrane channel opening (the proximate cause of physiological excitation) is not understood. In Limulus photoreceptors, where PI-hydrolysis is also central to transduction (Brown et al., 1984, Fein et al., 1984; 1988), light-sensitive channels appear to be gated by cGMP, since cGMP opens the light-dependent channels in excised membrane patches, while

\footnotetext{
Received Mar. 31, 1995; revised Aug. 2, 1995; accepted Aug. 4, 1995.

We are grateful to Dr. C. S. Zuker and to B. Niemeyer for generous help and advice with preparation and recording. We also gratefully acknowledge gifts of strains Canton S (Dr. W. L. Pak) and Oregon R (Dr. D. R. Hyde). We thank Dr. Cecilia Vergara, Dr. Judith S. Eisen, and Dr. Mark P. Gray-Keller for critical reading of the manuscript. Funding was from U. S. National Institutes of Hcalth EY09388 (P.M.O.), U. S. National Science Foundation INT9301719 (P.M.O. and J.B.), and Programa de Cooperacion Cientifica Internacional Fundacion Andes/CONICYT (J.B. and P.M.O.).

Correspondence should be addressed to Dr. Peter M. O'Day at the above address.

Copyright 1995 Society for Neuroscience $0270-6474 / 95 / 157196-05 \$ 05.00 / 0$
}

$\mathrm{Ca}^{2+}$ does not (Bacigalupo et al., 1990; 1991). Furthermore, experimental evidence indicates that blockers of guanylate cyclase and cGMP-PDE in Limulus photoreceptors alter light-induced excitation in a $\mathrm{Ca}^{2+}$-dependent fashion (O'Day, 1991; Inoue et al., 1992; Johnson and O'Day, unpublished observations). These results suggest a link between PI-hydrolysis and cGMP metabolism. On the other hand, PI chemistry may also be involved in adaptation processes in the retina, regulating photoreceptor light sensitivity (Ranganathan et al., 1991a; Smith et al., 1991; Hardie et al., 1993); however, specific cellular mechanisms are not fully understood.

In the present work, we investigated the possibility that cGMP plays a role in Drosophila visual transduction. To address this question, we have examined the physiological effects of external application of a membrane permeant and poorly hydrolyzable form of cGMP, 8-Br-cGMP, to photoreceptors from Drosophila retina. Specifically, we have studied the effect of a low-pressure puff of 8-Br-cGMP on membrane currents and on light-induced excitation under whole cell voltage clamp.

\section{Materials and Methods}

Dissection of late pupal Drosophila was done under dim red illumination. Wild type strains Oregon-R (red eye and white eye) and Canton $S$ (red eye) flies were used in all experiments reported. Phenotypes were confirmed by electroretinogram (Blake et al., 1991). Heads were removed and transferred to dissociation solution $(120 \mathrm{~mm} \mathrm{NaCl}, 10 \mathrm{~mm}$ HEPES, $4 \mathrm{~mm} \mathrm{KCl,} 32 \mathrm{~mm}$ sucrose, $\mathrm{pH} 7.15$, oxygenated). The eyes were dissected out and the retinas were mechanically shredded on a glass coverslip, in a drop or dissociation solution. Surviving intact cell clusters settled to the bottom. The coverslip was transferred to a recording chamber on the microscope stage and the preparation was diluted $\sim 30-50$-fold with bath solution ( $120 \mathrm{~mm} \mathrm{NaCl}, 10 \mathrm{~mm}$ HEPES, $8 \mathrm{mM} \mathrm{MgSO}_{4}, 5 \mathrm{mM} \mathrm{KCl}, 25 \mathrm{mM}$ L-proline, $2.5 \mathrm{~mm}$ sucrose, $1.5 \mathrm{~mm}$ $\mathrm{CaCl}_{2}, \mathrm{pH} 7.15$, oxygenated). To view cells in dark-adapted conditions, we used infrared $(>800 \mathrm{~nm}$ ) illumination and an infrared-sensitive CCD video camera attached to an inverted microscope (40× Nikon ELWD objective) and connected to a video monitor. White light (Osram halogen xenophot HLX\#64625) was used as excitation light, as described previously (O'Day et al., 1991). Light intensities are described in ND (neutral density units); -1.0 ND corresponds to a $1 \log _{10}$ unit attenuation from maximal intensity of $1.2 \mathrm{~mW} / \mathrm{cm}^{2}$. A patch clamp (Axopatch $200 \mathrm{~A}$, Axon Instruments, Inc.) was used in whole-cell mode for voltageclamping the cells (Hamill et al., 1981; Hardie, 1991). Patch pipettes were filled with internal solution $(124 \mathrm{~mm} \mathrm{CsCl}, 10 \mathrm{~mm}$ HEPES, $2 \mathrm{~mm}$ $\mathrm{MgSO}_{4}, 1.1 \mathrm{~mm}$ EGTA, $0.1 \mathrm{~mm} \mathrm{CaCl}, 0.5 \mathrm{~mm}$ GTP, $2 \mathrm{~mm}$ ATP, pH 7.15 , oxygenated). Seal resistances were typically $5 \mathrm{G} \Omega$ or higher, and input resistances were $500 \mathrm{M} \Omega$ to $1.2 \mathrm{G} \Omega$ Data were low pass filtered with an 8-pole Bessel filter and acquired digitally (Labmaster A/D, Scientific Solutions, Inc.) and stored on computer. Some data were filtered digitally during analysis (pCLAMP 6.0, Axon Instruments, Inc.), and lowpass filtering frequencies are listed in each figure caption. In addition. data were stored on magnetic tape with a VCR, interfaced with a digital data recorder (VR-10, Instrutech Corp.). Data were also stored by strip 
$\Lambda$
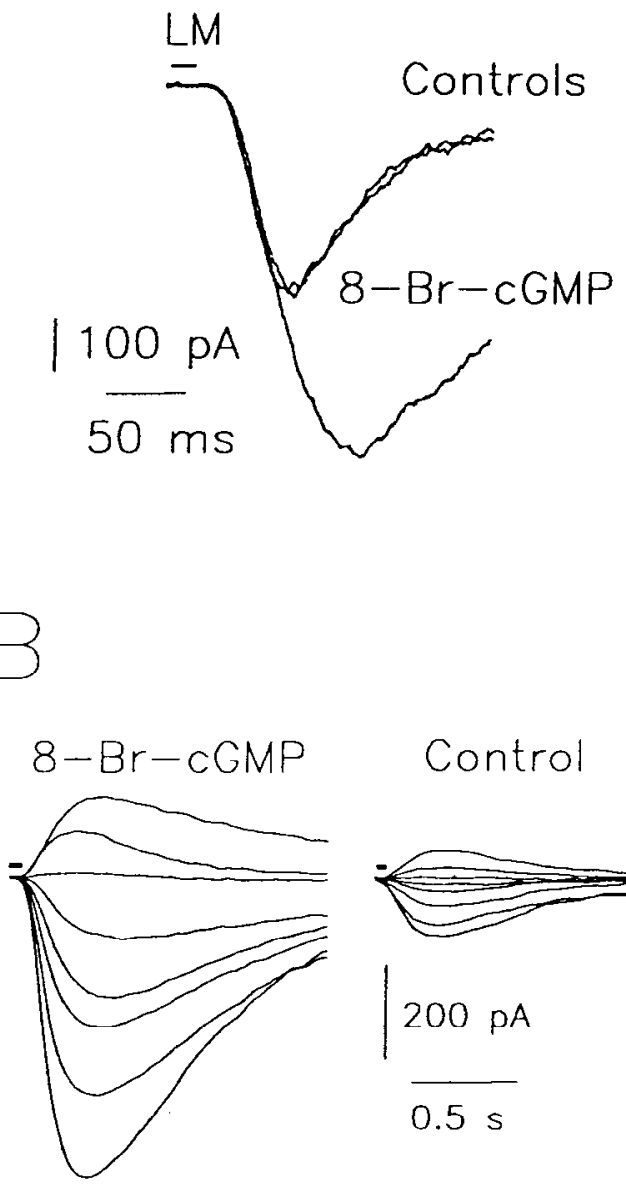

Control
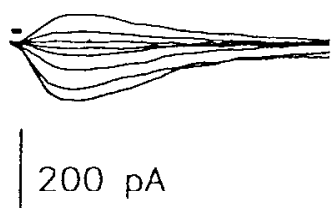

$0.5 s$

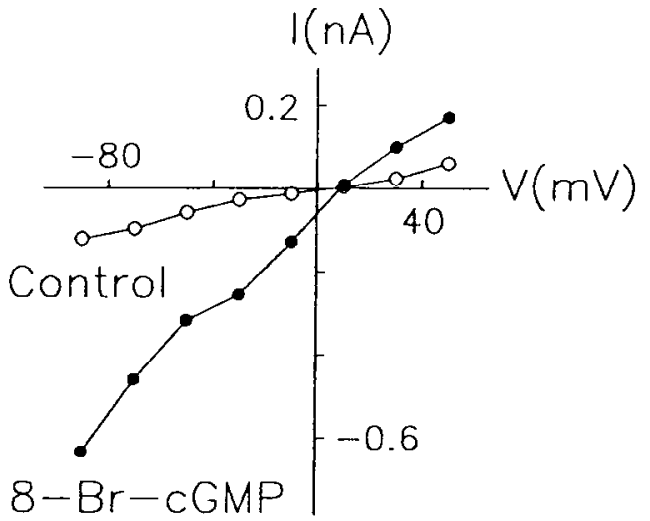

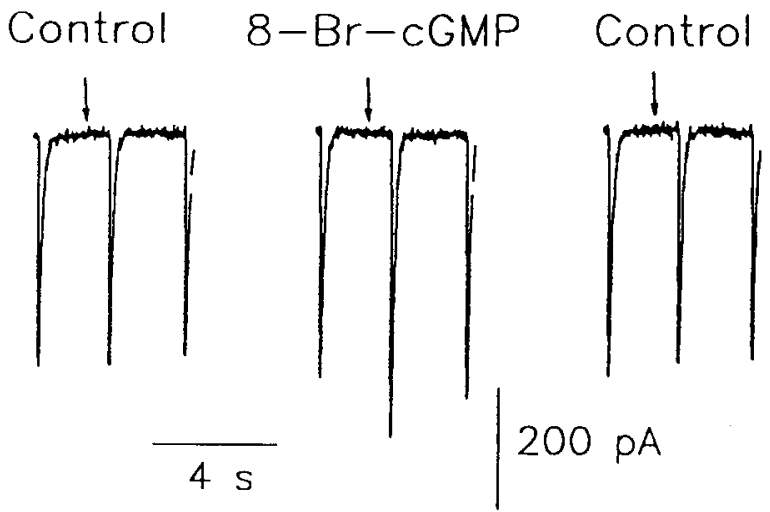
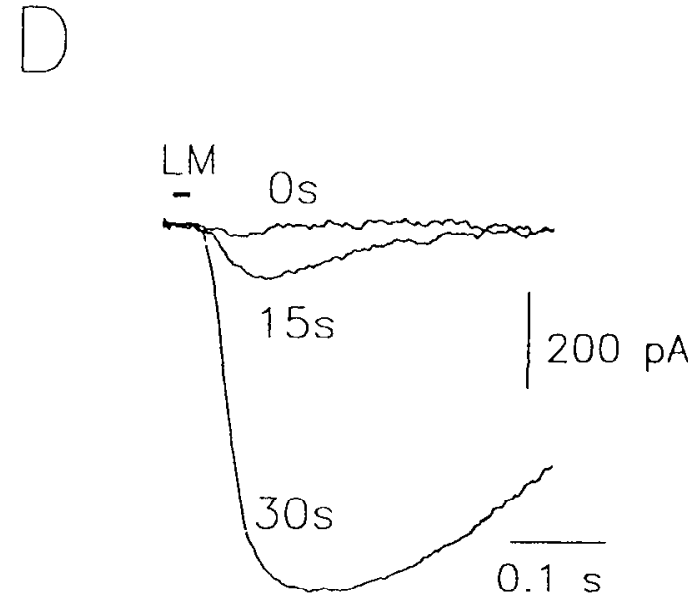

Figure 1. Cyclic-GMP enhanced light responses. 8-Br-cGMP was applied extracellularly to photoreceptors voltage clamped to $-70 \mathrm{mV}$. $A$, Superimposed responses to test flashes $(-3.0 \mathrm{ND}, 10 \mathrm{msec})$ during a puff of control solution, during subsequent 8 - $\mathrm{Br}$-cGMP puff, and during return to control puff. Enhancement was observed in 20 photoreceptors from white eyed Oregon- $R$ flies assayed in this fashion, 12 of which exhibited greater than twofold enhancement. We obtained similar results with red-eyed Oregon $\mathbf{R}$ and Canton $S$ strains. We have observed no enhancement by control solutions. LM indicates light monitor in all figures. Currents were filtered at $100 \mathrm{~Hz}$. B, Current-voltage relation of light-induced currents before and during 8-Br-cGMP application. Reversal voltage was essentially unchanged. Current traces were generated during $10 \mathrm{sec}$ voltage-clamp pulses from $V_{\text {pise }}=-90 \mathrm{mV}$ to $+50 \mathrm{mV}$ in $20 \mathrm{mV}$ increments (interpulse $V_{H}=-70 \mathrm{mV}$ ). Currents were filtered at $10 \mathrm{~Hz}$. Peak light-induced currents are plotted versus $V_{m}$ before and during enhancement. Voltage-activated currents have been subtracted digitally. $C$, Enhancement resulting from brief $(40 \mathrm{msec}) 8-\mathrm{Br}$-cGMP puff (arrows) applied between test flash stimuli. The response to the second test flash in the sequence was significantly larger than the preceding and following responses. Currents were filtered at $10 \mathrm{kHz}$. We observed no enhancement with control puffs. Similar results were obtained in 12 trials. $D, 8-\mathrm{Br}$-cGMP rescued responsiveness to test flashes. Three test flash responses, starting at the initiation of 8-Br-cGMP application and separated by $15 \mathrm{sec}$ intervals, are superimposed for comparison. $V_{H}=-70 \mathrm{mV}$. Currents were filtered at $100 \mathrm{~Hz}$. Similar results were obtained in six cells. 

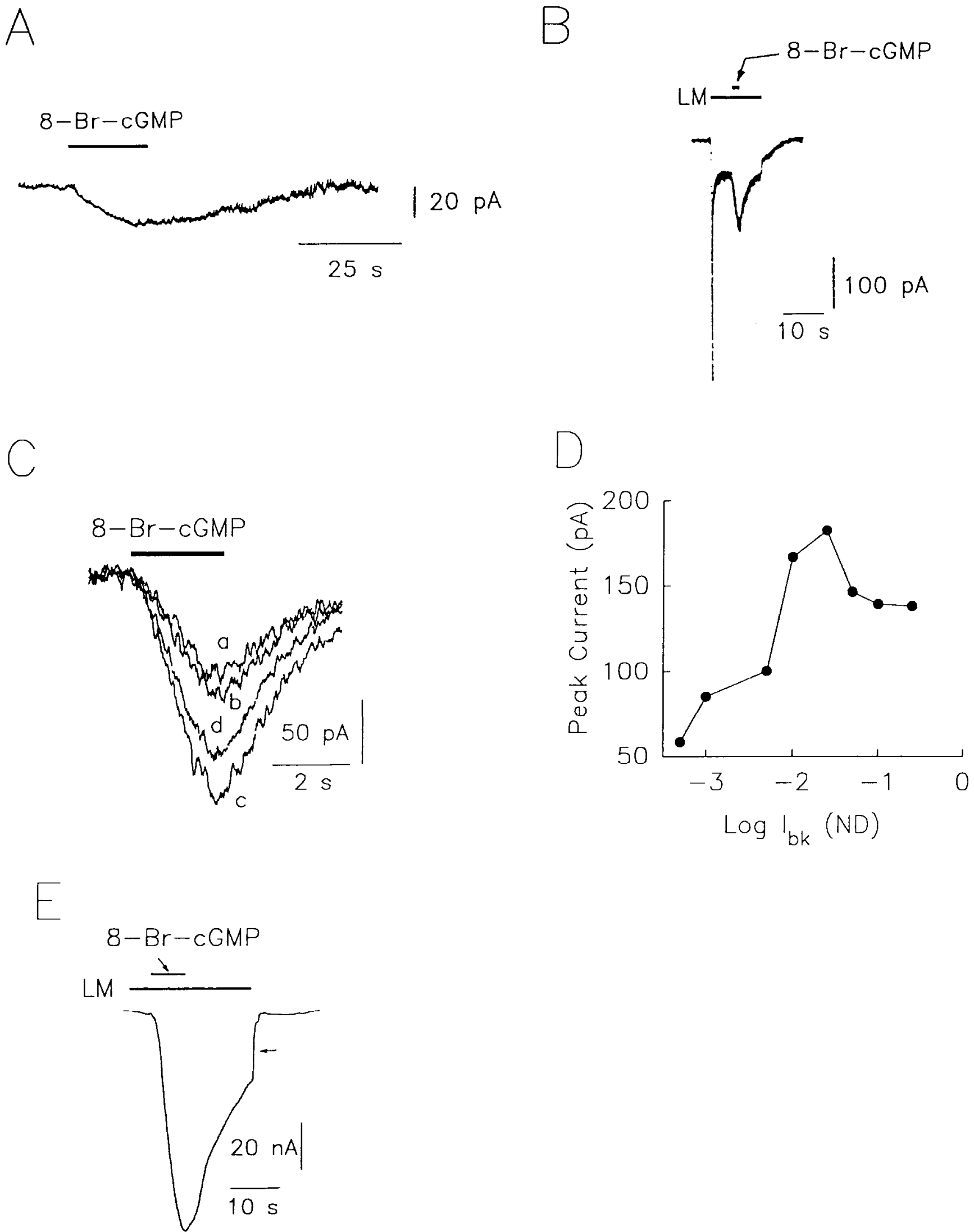

Figure 2. Currents induced by 8-Br-cGMP. $A, 8$-Br-cGMP induced membrane currents in the dark $\left(V_{H}=-70 \mathrm{mV}\right)$. Currents were filtered at 10 $\mathrm{kHz}$. Similar results were observed in 10 cells. $B, 8-\mathrm{Br}$-cGMP induced membrane currents $\left(V_{H}=-70 \mathrm{mV}\right)$ during background illumination (bar; $-2.0 \mathrm{ND}, 12 \mathrm{sec}$ ). The response to background illumination possesses transient and plateau phases. Five seconds after the onset of light (during the plateau phase), an 8-Br-cGMP puff was gently applied (arrow), inducing an incremental transient inward current. Currents were filtered at 10 $\mathrm{kHz}$. $C$, Comparison of 8-Br-cGMP responses elicited during background illumination of various intensities $I_{\mathrm{b}}$, using an identical 8-Br-cGMP puff each time. Currents (filtered at $1 \mathrm{kHz}$ ) are superimposed, after subtracting the plateau currents. $a,-3.0 \mathrm{ND} ; b,-2.0 \mathrm{ND} ; c,-1.6 \mathrm{ND} ; d,-1.0$ 
chart recorder (Gould, Inc.). Membrane permeant 8-Br-cGMP (8-bromoguanosine $3^{\prime}: 5^{\prime}$-cyclic monophosphate, Sigma Chemical Co.; or Calbiochem-Novabiochem Corp.) was applied by gentle puff (similar to Frings and Lindenann, 1991) from one port of a double barreled glass pipette (spritzer; diam. $\sim 5-10 \mu \mathrm{m}$ ) filled with external solution containing $2 \mathrm{mM} 8$-Br-cGMP; the other port contained control solution. The control solution in all experiments reported in Figures 1 and 2 was the external solution described above. However, in further controls, we repeated the experiments described in Figures $1 A$ and $2 A$ with the control port filled with $2 \mathrm{mM} 8$-Br-GMP (8-bromoguanosine 5 '-monophosphate, Sigma) and separately with the control port filled with $2 \mathrm{mM} 8$-Br-AMP (8-bromoadennsine 5 -monophosphate, Sigma). In both cases, we found 8-Br-cGMP induced effects (as in Figs. $1 A$ and $2 A$ ) but no effect of control puffs. The pipette was positioned $50-70 \mu \mathrm{m}$ from the cell cluster under examination. Pressure (1 3 psi) was provided by a picospritzer.

\section{Results}

Figure 1 illustrates that 8 -Br-cGMP reversibly enhanced responses to light. The amplitude of the light responses increased during 8-Br-cGMP exposure, whereas the latency and activation phase were not affected (Fig. 1A). The kinetics of response recovery were retarded in the experiment shown in Figure 1; however, such slowing was not uniformly observed. In some cases, response recovery was unaffected, and in a small number of cases it was accelerated. The reversal potential of the light response was also unaffected. Figure $1 B$ shows light responses at several holding voltages, $V_{H}$, illustrating that the reversal potentials before and during 8 -Br-cGMP were indistinguishable.

The effect of 8 -Br-cGMP was quite fast. A brief ( $40 \mathrm{msec}$ ) puff of 8 -Br-cGMP, presented during the interval between two of a series of consecutive flashes, reversibly enhanced the second test flash response, whereas an identical puff of control solution had no effect (Fig. $1 C$ ). The cGMP-induced enhancement of light responses suggests that processes underlying transduction are sensitive to cGMP. The degree of the cGMP-induced enhancement was quite variable. In most cells the light-response enhancement was twofold or greater. In a few cells that appeared unresponsive to even the brightest flashes, 8-Br-cGMP restored their ability to respond to subsequent test flashes. Figure $1 D$ illustrates the gradual development of light sensitivity by continued application of 8-Br-cGMP in one such cell.

We examined whether 8 -Br-cGMP could induce membrane currents in darkness. In cells voltage-clamped to $-70 \mathrm{mV}$ in the dark, 8-Br-cGMP often induced inward currents (Fig. 2A). The reversal voltage of these currents was similar to that of lightinduced currents (between $0 \mathrm{mV}$ and $+20 \mathrm{mV}$ ). This result raises the possibility that both light and CGMP activate the same conductance. When a brief puff of 8 -Br-cGMP was delivered during exposure to background illumination (Fig. 2B), a transient inward current developed. The amplitudes of cGMP-induced currents increased with increasing background light intensity, $I_{\mathrm{hk}}$ (Fig. $2 C$ ), reached a maximum under moderate intensity illumination, and decreased under very bright illumination (Fig. 2D).

Figure $2 E$ illustrates directly that 8 -Br-cGMP can affect lightdependent excitation. The cell under study was only weakly responsive to light stimuli; a moderately bright light was insufficient to induce excitation. However, in response to introduction of 8-Br-cGMP during steady illumination, a large inward current developed. The current declined gradually after the end of the cGMP stimulus, but its decline to baseline hecame abrupt after the offset of light.

\section{Discussion}

Our observations are consistent with the idea that a cGMP-sensitive process is an integral part of transduction. Light-induced excitation is sensitive to cGMP, and cGMP induces a current that is sensitive to light.

cGMP may play a direct role in excitation, either as a gating ligand of light-dependent channels, as in Limulus (Bacigalupo et al., 1991), or acting at some earlier step in the excitation cascade. If cGMP is a channel ligand, one might expect a sigmoidal dependence of cGMP-induced current on [cGMP] if more than one nucleotide molecule is required to open each channel, as in the cGMP-dependent channel of vertebrate photoreceptors (Haynes et al., 1986) and the cAMP-dependent channel of olfactory ncurons (Zufall ct al., 1991). Sigmoidal dependence would yield in essence a threshold phenomenon. In this situation, low levels of exogenous 8-Br-cGMP would fail to activate enough channels to produce a detectable current. However, the same subthreshold 8 -Br-cGMP application would enhance light responses if it elevated total [cGMP] (endogenous lightdependent [cGMP] + exogenous [8-Br-cGMP]) to a level at which the sigmoidal curve relating current to [cGMP] steepens. At very high background intensities, the effect of exogenous 8-Br-cGMP would in principle be reduced as saturation is approached. However, it seems unlikely that this occurs, because our largest 8-Br-cGMP induced currents are well below saturation (compare the light-induced current with the cGMP-induced current in Fig. $2 A$ ). One possible reason for the decline in $8-\mathrm{Br}$ cGMP induced current amplitudes at high $I_{\mathrm{bk}}$ is that intracellular $\mathrm{Ca}^{2+}$, greatly elevated by bright illumination (Peretz et al., 1994; Ranganathan et al., 1994), might reduce channel activity, as proposed for Limulus photoreceptors (Johnson and Bacigalupo, 1992).

Another possibility is that enhancement of light responses by 8-Br-cGMP could be due to an inhibitory effect on light adaptation. However, the fact that enhancement was not accompanied by a change in response activation kinetics (Hardie et al., 1993) characteristic of adaptation makes this possibility seem less likely.

An alternative or additional role of cGMP early in transduction is conceivable, possibly regulating the PI-pathway or acting in a parallel excitation pathway. Several lines of evidence support the idea of parallel pathways in invertebrate transduction (Payne and Fein, 1986; Frank and Fein, 1991; Shin et al., 1993; Johnson and O'Day, unpublished observations), perhaps involving two or more classes of light-activated channels (Hardie and Minke, 1992; Deckert et al., 1992; Nasi, 1991; Nasi and Gomez, 1992). In this case, cGMP may gate one class of channel and have an additional modulatory role on another (or even on the same) pathway, thus enhancing the light-response. Alternatively, light may produce two second messengers, cGMP and another $\longleftarrow$

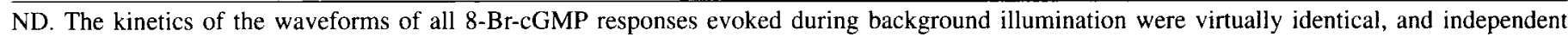

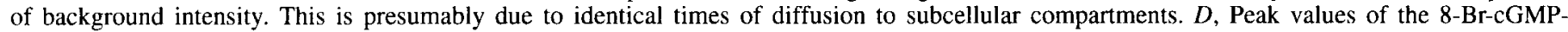

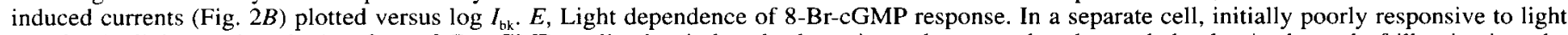

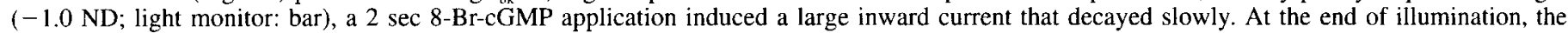
decay of the current was much faster (arrow). Currents were filtered at $10 \mathrm{~Hz}$. 
(perhaps $\mathrm{Ca}^{2+}$ ), whose synergistic action would be required to open channels. In this regard, it is interesting to note the recent reports (1) that artificial elevation of $\left[\mathrm{Ca}^{+}\right]_{i}$ does not by itself induce membrane currents (Hardie, 1995) and (2) that artificial elevation of $\left[\mathrm{Ca}^{+}\right]_{i}$ with thapsigargin does not induce excitation or greatly affect light-induced excitation (Ranganathan et al., 1994).

Two recent findings bolster the notion of cGMP involvement in Drosophila transduction: a Drosophila retinal gene encoding the $\beta$-subunit of a soluble guanylate cyclase (Yoshikawa et al., 1993) and the cloning and functional expression of a cGMPgated channel gene from Drosophila retina (Baumann et al., 1994). Phototransduction in Drosophila may thus resemble that in Limulus ventral eyes by virtue of the involvement of both cGMP and PI metabolism (Inoue et al., 1992; O'Day, 1991).

\section{References}

Bacigalupo J, Johnson EC, Robinson PR, Lisman JE (1990) Second messengers in invertebrate phototransduction. In: Transduction in biological systems (Hidalgo C, Bacigalupo J, Jaimovich E, Vergara J, eds), pp 27-45. New York: Plenum

Bacigalupo J, Johnson EC, Vergara C, Lisman JE (1991) Light-dependent channels from excised patches of Limulus ventral photoreceptors are opened by cyclic GMP. Proc Natl Acad Sci USA 88:7938-7942.

Baumann A, Frings S, Godde M, Seifert R, Kaupp UB (1994) Primary structure and functional expression of a Drosophila cyclic nucleotide gated channel present in eyes and antennae. EMBO J 13:5040-5050.

Blake A, Bernstein L, O'Day PM, Lonergan M, Venkatesh TR (1991) A mutation at the fur, fused rhabdomeres, locus alters rhabdomere morphology and photoreceptor function in Drosophila melanogaster. J Neurogenet 7:213-228.

Brown JE, Rubin LJ, Ghalayini AJ, Tarver AL, Irvine RF, Berridge MJ, Anderson RE (1984) Myo-inositol polyphosphate may be a messenger for visual excitation in Limulus ventral photoreceptors. Nature $311: 160-162$.

Deckert A, Nagy K, Helrich CS, Stieve H (1992) Three components of the light-induced current of the Limulus ventral photoreceptor. J Physiol (Lond) 453:69-96.

Devary O, Heichal O, Blumenfeld A, Cassel A, Barash A, Rubinstein T, Minke B, Selinger Z (1987) Coupling of photoexcited rhodopsin to phosphoinositide hydrolysis in fly photoreceptors. Proc Natl Acad Sci USA 84:6939-6943.

Dolph PJ, Ranganathan R, Colley NJ, Hardy RW, Socolich M, Zuker CS (1993) Arrestin function in inactivation of G-protein coupled receptor rhodopsin in vivo. Science 260:1910-1916.

Fein A. Payne R, Corson DW, Berridge MJ, Irvine RF (1984) Photoreceptor excitation and adaptation by inositol 1,4,5-trisphosphate. $\mathrm{Na}$ ture $311: 157-160$

Frank T, Fein $\Lambda$ (1991) The role of the inositol phosphate cascade in visual excitation in invertebrate microvillar photoreceptors. J Gen Physiol 97:697-724

Frings S, Lindemann B (1991) Current recording from sensory cilia of olfactory cells in situ. I. neuronal response to cyclic nucleotides. J Gen Physiol 97:1-16.

Hamill OP, Marty A, Neher E, Sakmann B, Sigworth FJ (1981) Improved patch-clamp techniques for high-resolution current recording from cells and cell-free membrane patches. Pfluegers Arch Eur J Physiol 391:85-100.

Hardie RC (1991) Whole-cell recordings of the light induced current in dissociated Drosophila photoreceptors: evidence for feedback by calcium permeating the light-sensitive channels. Proc $\mathrm{R}$ Soc Lond [Biol] 245:203-210.

Hardie RC (1995) Caged $\mathrm{Ca}^{2+}$ facilitates and inactivates but does not dirctly excite light sensitive channels in Drosophila photoreceptors. J Neurosci 15:889-902.

Hardie RC, Minke B (1992) The trp gene is essential for a lightactivated $\mathrm{Ca}^{2+}$ channel in Drosophila photoreceptors. Neuron 8:643651

Hardie RC, Minke B (1993) Novel $\mathrm{Ca}^{2+}$ channels underlying transduction in Drosophila photoreceptors: implications for inositide-mediated $\mathrm{Ca}^{2+}$ mobilization. Trends Neurosci 16:371-376.

Hardie RC, Peretz A, Suss-Toby E, Rom-Glas A, Bishop SA, Selinger $\mathrm{Z}$ (1993) Protein kinase $\mathrm{C}$ is required for light adaptation in Drosophila photoreceptors. Nature 363:634-637.

Haynes LW, Kay AR, Yau K-W (1986) Single cyclic GMP-activated channel activity in excised patches of rod outer segment membrane. Nature 321:66-70.

Johnson EC, Bacigalupo I (1992) Spontaneous activity of the lightdependent channel irreversibly induced in excised patches from $\mathrm{Li}$ mulus ventral photoreceptors. J Membr Biol 130:33-47.

Inoue M, Ackermann K, Brown JE (1992) Cyclic GMP phosphodies terase and photoreceptor cells in Limulus ventral eye. In: Signal transduction in photoreceptor cells (Hargrave PA, Hofmann KP, Kaupp UB, cds), pp 271-280. Berlin: Springer.

Lee Y-J, Dobbs MB, Verardi ML, Hyde DR (1990) dgq: a Drosophila gene encoding a visual system specific $\mathrm{G}_{\mathrm{w}}$ molecule. Neuron 5:889_ 898

Lee Y-J, Shah S, Suzuki E, Zars T, O'Day PM, Hyde DR (1994) The Drosophila $d g q$ gene encodes $\mathrm{a}_{\mathrm{a}}$ protein that mediates phototransduction. Neuron 13:1143-1157.

Nasi E (1991) Two light-dependent conductances in Lima rhabdomeric photoreceptors. J Gen Physiol 97:55-72.

Nasi E, Gomez M (1992) Light-activated ion channels in solitary photoreceptors of the scallop Pecten irradians. J Gen Physiol 99:747769.

O'Day PM (1991) Sodium/Calcium exchange in invertebrate photoreceptors. Ann NY Acad Sci 639:285-299.

O'Day PM, Gray-Keller MP, Lonergan M (1991) Physiological roles of $\mathrm{Na}^{+} / \mathrm{Ca}^{2+}$-exchange in Limulus ventral photoreceptors. J Gen Physiol 97:1-23.

Payne R, Fein A (1986) The initial response of Limulus ventral photoreceptors to bright flashes: released calcium as a synergist to excitation. J Gen Physiol 87:243-269.

Payne R, Walz B, Levy S, Fein A (1988) The localization of calcium release by inositol trisphosphate in Limulus photoreceptors and its control by negative feedback. Philos Trans R Soc Lond [Biol] 320: 359-379.

Peretz A, Suss-Toby E, Rom-Glas A, Arnon A, Payne R, Minke B (1994) The light response of Drosophila photoreceptor is accompanied by an increase in cellular calcium: effects of specific mutations. Neuron 12:1257-1267.

Ranganathan R, Harris GL, Stevens CF, Zuker CS (1991a) A Drosophila mutant defective in extracellular calcium-dependent photoreceptor deactivation and rapid desensitization. Nature 354:230-232.

Ranganathan R, Harris WA, Zuker CS (1991b) The molecular genetics of invertebrate phototransduction. Trends Neurosci 14:486-493.

Ranganathan R, Bacskai BJ, Tsien RY, Zuker CS (1994) Cytosolic calcium transients: spatial localization and role in Drosophila photoreceptor cell function. Neuron 13:837-848.

Selinger Z, Minke B (1988) Inositol lipid cascade of vision studied in mutant flies. Cold Spring Harbor Symp Quant Biol 53:333-341.

Shin J, Richard EA, Lisman JE (1993) $\mathrm{Ca}^{2+}$ is an obligatory intermediate in the excitation cascade of Limulus photoreceptors. Neuron 11:845-855.

Smith DP, Ranganathan R, Hardy RW, Marx J, Tsuchida T, Zuker CS (1991) Photoreceptor deactivation and retinal degeneration mediated by a photoreceptor-specific protein kinase C. Science 254:1478-1484.

Yoshikawa S, Miyamoto I, Aruga J, Furuichi T, Okano H, Mikoshiba K (1993) Isolation of a Drosophila gene encoding a head-specific guanylyl cyclase. J Neurochem 60:1570-1573.

Zufall F, Firestein S, Shepherd GM (1991) Analysis of single cyclic nucleotide-gated channels in olfactory receptor cells. J Neurosci 11: $3573-3580$. 